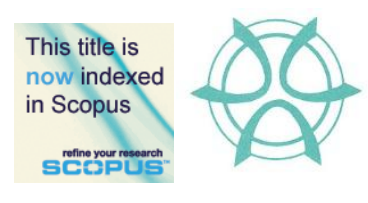

PLANNING MALAYSIA:

Journal of the Malaysian Institute of Planners

Volume XII (2014), Page 1 - 18

\title{
EVALUATING THE IMPACT OF DENSITY ON ACCESS TO LOCAL FACILITIES IN URBAN NEIGHBOURHOODS
}

\author{
Wan Nurul Mardiah Wan Mohd Rani ${ }^{1}$ \\ UTM Razak School of Engineering and Advanced Technology \\ UNIVERSITI TEKNOLOGI MALAYSIA
}

\begin{abstract}
Local services and facilities in residential neighbourhoods play an important role towards the social sustainability of local residents. It is believed that having good provision and access to these local services and facilities would contribute significantly to the quality of life and residents' well-being. The form of the neighbourhood influences the way people live in the neighbourhood. The way people settle in neighbourhood's shapes the quality of life, the richness of the local economy, the level of social cohesion, the level of safety and the amount and the kind of human activities in public spaces. Different urban forms can have very different degrees of sustainability. Density is one of the urban form elements that have been research numerous times and proven to have an influence on the neighbourhood sustainability. Density is the most easily measured urban form element either at a macro level (city) or micro level (neighbourhood). This research discusses the impact of density on the micro scale through estimating its influence on access to local facilities. Through the use of household survey and supported by observation survey, this study findings on the impact of density on access and use of local facilities. The study concludes with establishing the findings of the survey to reflect and fit into the body of knowledge and how it would improve the guidelines and policy on social sustainability in improving the urban living as a whole.
\end{abstract}

Keyword: Density, urban form, social sustainability; access to services and local facilities

\footnotetext{
${ }^{1}$ Senior Lecturer. Built Environment Panel, Department of Science Management and Design. Email:wnurul.kl@utm.my
} 
Wan Nurul Mardiah Wan Mohd Rani

Evaluating the Impact of Density on Access to Local Facilities in Urban Neighbourhoods

\section{INTRODUCTION}

In recent years, Malaysia has put great effort in moving towards a more sustainable urban environment. This is associated with the vision to place Malaysians on a par with societies in developed nations and to develop a progressive and inclusive society (Prime Minister's Office, 2011; Malaysia, 2010, p. 178). A 'progressive society' was described as "one that balances personal needs and civil liberties to ensure the rights of its citizens are upheld and respected" (Malaysia, 2010, p. 178). Malaysian policymakers have put emphasis on the policies related to social issues to show their concern on the importance to move towards social sustainability particularly in the urban environment setting. On the subject of urban sustainability, social issues are one of the most discussed aspects. This is because social equity and sustainability of the community are most affected by the changes in urban form as a result of the urbanization process. Moreover, the physical form of cities influences the way society lives and interact in cities. In relation to social sustainability, major cities in Malaysia are deemed to be affected by rapid urbanization. The costs and benefits of living in urban areas are still uncertain. Understanding urban form and its relation to aspects of sustainability is essential to understanding the impact of urbanization on our daily social life. However, there has been little discussion or research into this matter in the Malaysian context, in comparison to some developed countries such as the United Kingdom and United States where this issue has gained much attention and a lot of research has been done. Hence, there is a need to explore the issue of social sustainability in relation to urban form aspects in Malaysia.

\section{RESEARCH BACKGROUND}

The study focuses on how density impacts social sustainability in a neighbourhood scale specifically focusing on access to local services and facilities. The hypothesis for this study is 'Higher density would result in improved access to services and public facilities'. This hypothesis is in line with many previous studies that claimed density is the overall urban form measure that can explain improved access (Bramley, Dempsey et al. 2009; Bramley and Power 2009; Jenks and Jones, 2010). However, findings by Burton (2000a, 2000b and 2003) were mixed across different services. The role of local facilities in urban areas is very crucial as it would indefinitely 
increase the quality of urban living. Abdul Rahman et al. (2012) explains that what constitutes a healthy urban neighbourhoods are the relationship and interactions between the local communities with mixed land use and facilities. Generally, the main purpose of this study is to obtain a better understanding of the impact of urban form on social sustainability in Malaysia.

"In terms of social facilities, it was found that the provision of recreational areas is generally inadequate for all towns in Malaysia. Moreover, there is a problem of maintenance of the facilities as well as being non-user friendly since the location and design of facilities do not take into account the needs of certain segments of the society such as the disabled, children and elderly.

Vandalism of public properties also exists and leads to not fully utilized facilities".

(Federal Department of Town and Country Planning, Peninsular Malaysia, 2006, p. 28)

Specifically, the interest to explore this research arises from concern about the potential impact of rapid urban growth and changing urban form of major cities in Malaysia on social sustainability. Currently, major cities in Malaysia are experiencing rapid development growth which has resulted in numerous urban problems. These include social problems, traffic congestions, environmental degradation, and economic instability.

The study was conducted in two major cities in Malaysia: the Federal Territory of Kuala Lumpur and the Federal Territory of Putrajaya. These two cities were chosen because of their distinctive characters. In brief, the reason for selection was due to the contrast of the two cities, i.e. older and unplanned city (Kuala Lumpur) versus modern planned city (Putrajaya); the experience of rapid growth in both cities and finally, due to the ease for the researcher to facilitate field survey logistically.

In the case study city of Kuala Lumpur, the survey areas focus on three sub areas which have been categorized according to inner, intermediate and outer sub area located within Wangsa Maju-Maluri Strategic Zones. Wangsa Maju-Maluri Strategic Zone is defined in the north by the boundary of Kuala Lumpur, which separates the City from Batu Caves, Gombak, and Ampang areas in Selangor. Definition of the sub areas was defined by the geographical proximity of the sub area of the city center (CBD) and local knowledge, which was also applied in the City Form UK study (Jenks and Colins (Ed), 2010). Inner sub area refers to the Datuk Keramat which is also known as the village in the town. It is one of the oldest residential villages in 
Wan Nurul Mardiah Wan Mohd Rani

Evaluating the Impact of Density on Access to Local Facilities in Urban Neighbourhoods

Kuala Lumpur. Intermediate sub area refers to Taman Setiawangsa which is located approximately $5 \mathrm{~km}$ from Kuala Lumpur City Centre. Finally the outer sub area refers to Taman Wangsa Melawati which is approximately 7 $10 \mathrm{~km}$ from the city centre. Using a similar approach to Kuala Lumpur City, the survey in Putrajaya also focuses on three sub areas within the Putrajaya City with areas defined as inner, intermediate and outer area based on their proximity to the Putrajaya core area (Precinct 1-3) and local knowledge. Also, in this study, density is one of the urban form variables used to assess the usage pattern and access to the selected local services and public facilities. A three level density measure was applied i.e. Low density, medium density and high density. The three categories were referred to and guided by the density levels provided by the Kuala Lumpur City Hall (see Table 3.1). The density variable was created based on assessment of the plans for each case study area.

\section{THE INFLUENCE OF DENSITY ON SOCIAL SUSTAINABILITY}

\section{Density and its application}

Density is one of the aspects of urban form that have been receiving more attention in the literature with regard to its social impact. This is due to the fact that density of any particular development has the potential to impact upon all aspects of social sustainability (Bramley and Power, 2008). Furthermore, density is also effectively the overall summary measure of urban form, particularly when related to the concept of compactness in opposition to sprawl. According to Jabareen (2006, p. 41), "the relationship between density and urban character is also based on the concept of practicable threshold". This implies that to make an urban area functional or viable, there needs to be a certain level of densities with certain numbers of people to generate the interaction needed. Density typically refers to a measure of the number of people living in a given area of land although it can also be measured in physical terms (e.g. Number of dwellings) (Towers, 2005).

Density also has some cultural dimensions as the density of where people live may be considered as relative (Dempsey, et al. in Jenks and Jones, 2010, p. 23). In the United Kingdom, the recent English housing policy stated that new residential development should have a minimum of 30 dwellings/ ha. This is considered high in some areas and low to some others (Dempsey, et al in Jenks and Jones, 2010, p. 23). On the other hand, Hong Kong, a minimum of 300 dwellings/ha is still considered as low density 
PLANNING MALAYSIA

Journal of the Malaysia Institute of Planners (2014)

(Jenks, 2000; Jenks and Dempsey, 2005). Richardson et al (in Burgess and Jenks, 2000) affirmed that densities in developing countries are much higher compared to developed countries, especially in the core cities including in Malaysian cities.

\section{Density - Malaysian Context}

Malaysia, as one of the developing countries also has significantly higher density in most of its major cities i.e. Kuala Lumpur. In Malaysia, most of the local councils are guided by the following table for density classification (Kuala Lumpur Local Plan). Referring to Table 3.1, it shows that what is considered low density in Hong Kong is considered as medium density in Malaysian cities. In comparison to UK cities, for a residential building of a minimum of 30 dwellings/ ha in Malaysia, this would be considered within the range of low density. This indicates that the cultural dimension of density in Malaysia can be regarded as moderate.

Table 1: Density Control in Residential Zones in most Malaysian Cities

\begin{tabular}{lcc}
\hline & \multicolumn{2}{c}{ Maximum Density Allowable } \\
\cline { 2 - 3 } & Person/ha(pph) & Unit/ha \\
\hline Low density & 10 & 2 \\
& 40 & 7 \\
& 45 & 15 \\
Medium density & 100 & 20 \\
& 100 & 30 \\
High density & 200 & 50 \\
& 300 & 75 \\
\hline Public Housing & 300 & 80 \\
& 600 & 150 \\
& 850 & 200 \\
& 900 & 250 \\
\hline & 900 & 250 \\
\end{tabular}


Wan Nurul Mardiah Wan Mohd Rani

Evaluating the Impact of Density on Access to Local Facilities in Urban Neighbourhoods

\section{Density and its impact on social sustainability}

There are several ways on how density may impact on sustainability. Areas with higher density would give the opportunity to have better access to services and local facilities (Haughton and Hunter, 1994; Towers, 1996; Burton, 2000; Dempsey et al. 2012). Bramley et al. (2010, p. 111) stated that "there are reasons to expect access to services to be better in denser urban forms, while the quality of neighbourhood environment, community and social interaction may be less good in denser areas".

It was also claimed that higher density would promote commercial viability and therefore revived public realm (Talen, 1999). Similarly, Dempsey et.al (2012) also claimed that residential density impacts several aspects of social sustainability and positive influence on the use of local services and facilities is the most obvious. However, Bramley and Power (2009) argued that in terms of quality of neighbourhood environment, community, and social interaction it may be better in lower density areas. In terms of social interaction, higher density may provide more possibilities for people to meet each other on the street than slower density areas. However, beyond a certain level, high densities may make people feel that their personal space is compromised and the sheer number of people makes for anonymity (Dempsey et.al. 2011). Lower densities provide less potential for spontaneous interaction and lead to greater dependency on car travel (Bramley and Power, 2009).

Bramley and Power (2009) explained the way to measure the impact of density is to look at the density measures in terms of gross residential, which can be measured in terms of dwellings or habitable rooms per hectare. This is because using people per hectare would lead to confusion in terms of occupancy with physical form. Furthermore, it is difficult to measure the net density because of the nature of the census data that covers all types of land use and not only residential use (Bramley and Power 2009, p. 35). They further suggested that density is considered as the most important aspect of urban form because it is a general summary measure which many other features will be partly correlated with. 
PLANNING MALAYSIA

Journal of the Malaysia Institute of Planners (2014)

\section{METHODOLOGY}

The method used for this study is a mixed-method approach through two (2) case study areas. In the initial stage, it is important to understand the current urban form of the study areas and its transformation from the past. This was obtained through secondary sources such as development plans, structure plans, local plan, and other related government publications. Data on social characteristics was collected through a primary survey. Based on the information gathered from both primary and secondary sources, the researcher later evaluated and measured how density impacts the access and use to local services and facilities. For the purpose of this study, a household survey was conducted in the selected neighbourhood within two study cities of Kuala Lumpur and Putrajaya using random sampling. The targeted study population was local households/ adults and a random sample within the case study areas were interviewed using a structured questionnaire. The total number of questionnaire form distributed was approximately 2500 for both study areas. With the response rate of $43 \%$, the total number of respondents was 1084 . These data were complemented by information from an analysis of detailed maps/ plans and site observation survey. Descriptive statistics such as frequency distribution, cross tabulation, mean and standard deviation was used to analyse the data collected for the social characteristics and the respondents' satisfaction towards different aspects of urban form and access to services. Several findings were further tested using a range of statistical tests of associations. Regression and logistic regression models were used to identify factors affecting social sustainability, particularly urban form elements. This was used to identify and quantify the relationship between several independent variables of urban form and social sustainability indicators while controlling for other factors such as demographics.

\section{FINDINGS AND RESULTS}

\section{ACCESS TO LOCAL SERVICES AND FACILITIES}

\section{Influence of socioeconomic factor towards access to local services and facilities}

Finding of the study revealed the relationship between perceived access to local services and facilities with the household income group in the case study cities. For commercial facilities, it was revealed that for Kuala Lumpur, medium high income group (RM3001-RM5000) is the most likely to report better access to supermarket with $67 \%$. However, for the sundry / 
Wan Nurul Mardiah Wan Mohd Rani

Evaluating the Impact of Density on Access to Local Facilities in Urban Neighbourhoods

convenience shop, the medium low income group (RM1001-RM3000) is more likely to report having good access (96.4\%). The pattern is quite different for Putrajaya, where the lower income group (50.0\%) was more likely to report having good access to supermarket as compared to the higher income group $(27.5 \%)$. Through the chi-square analysis performed, this relationship was reported to be significant at $95 \%$ confidence level. No significant pattern was reported for the healthcare facilities. However, for the recreational facilities, in both case study cities, the playground was the most reported facility that have good access especially among the low income group with $92.2 \%$ in Kuala Lumpur (95\% confidence interval) and $100 \%$ for Putrajaya). Findings for other support services revealed an interesting finding for the religious facility (mosque), where more people among the lower income group $(94.1 \%$ in Kuala Lumpur and $85.7 \%$ for Putrajaya ) reports to have good access as compared to higher income group (90\% in Kuala Lumpur and $82.6 \%$ in Putrajaya).

Table 1: Cross tabulation between household income level and access to local services and facilities $(\%)$

\begin{tabular}{|c|c|c|c|c|c|}
\hline & & $\begin{array}{l}\text { Low } \\
\text { income } \\
\text { group }\end{array}$ & $\begin{array}{l}\text { Medium } \\
\text { low } \\
\text { income } \\
\text { group }\end{array}$ & $\begin{array}{l}\text { Medium } \\
\text { high } \\
\text { income } \\
\text { group }\end{array}$ & $\begin{array}{l}\text { High } \\
\text { Inco } \\
\text { me } \\
\text { group }\end{array}$ \\
\hline & & $(n=51)$ & $(n=253)$ & $(n=109)$ & $\begin{array}{l}(n=70 \\
)\end{array}$ \\
\hline \multirow{13}{*}{$\begin{array}{l}\text { Kuala } \\
\text { Lumpu } \\
r \\
\text { (N=48 } \\
3 \text { ) }\end{array}$} & \multicolumn{5}{|l|}{ Commercial Facilities } \\
\hline & Supermarket* & 54.9 & 60.5 & 67.0 & 64.3 \\
\hline & Sundry Shop & 90.2 & 96.4 & 95.4 & 92.9 \\
\hline & \multicolumn{5}{|l|}{ Healthcare facilities } \\
\hline & Private and Public Clinics & 72.5 & 70.0 & 65.1 & 65.7 \\
\hline & \multicolumn{5}{|l|}{ Recreational facilities } \\
\hline & Playground & 92.2 & 78.3 & 79.8 & 80.0 \\
\hline & Football field & 45.1 & 47.0 & 54.1 & 45.7 \\
\hline & Park/Garden* & 11.8 & 14.6 & 12.8 & 18.6 \\
\hline & \multicolumn{5}{|l|}{ Other Support Services } \\
\hline & Post office & 52.9 & 45.1 & 36.7 & 44.3 \\
\hline & Bank & 37.3 & 45.1 & 45.9 & 47.1 \\
\hline & Petrol Station*** & 33.3 & 55.7 & 54.1 & 65.7 \\
\hline
\end{tabular}


PLANNING MALAYSIA

Journal of the Malaysia Institute of Planners (2014)

\begin{tabular}{|c|c|c|c|c|c|}
\hline & Religious & 94.1 & 91.7 & 91.7 & 90.0 \\
\hline & & $(n=14)$ & $(n=182)$ & $(n=219)$ & $\begin{array}{l}(n=16 \\
7)\end{array}$ \\
\hline \multirow{14}{*}{$\begin{array}{l}\text { Putraja } \\
\text { ya } \\
(N=58 \\
2)\end{array}$} & \multicolumn{5}{|l|}{ Commercial Facilities } \\
\hline & Supermarket* & 50.0 & 34.6 & 39.7 & 27.5 \\
\hline & Sundry Shop & 64.3 & 87.4 & 83.6 & 85.0 \\
\hline & \multicolumn{5}{|l|}{ Healthcare facilities } \\
\hline & $\begin{array}{l}\text { Private and Public } \\
\text { Clinics** }\end{array}$ & 64.3 & 59.9 & 63.9 & 76.0 \\
\hline & \multicolumn{5}{|l|}{ Recreational facilities } \\
\hline & Playground* & 100.0 & 91.2 & 94.5 & 97.6 \\
\hline & Football field & 35.7 & 46.7 & 54.8 & 56.9 \\
\hline & Park/Garden* & 50.0 & 44.5 & 47.5 & 56.9 \\
\hline & \multicolumn{5}{|l|}{ Other Support Services } \\
\hline & Post office & 28.6 & 28.6 & 32.4 & 29.3 \\
\hline & Bank & 21.4 & 41.8 & 47.0 & 46.7 \\
\hline & Petrol Station*** & 64.3 & 73.6 & 79.9 & 86.8 \\
\hline & Religious & 85.7 & 84.6 & 82.2 & 82.6 \\
\hline
\end{tabular}

*indicates statistically significant at $10 \%$ level

** Statistically significant at 5\% level

*** statistically significant at $1 \%$ level

Table 2: Cross tabulation between car ownership and access to local services and facilities $(\%)$

$\begin{array}{ccc}\text { No Car } & \begin{array}{c}\text { Owns one } \\ \text { car }\end{array} & \begin{array}{c}\text { Owns two or } \\ \text { more cars }\end{array}\end{array}$

\begin{tabular}{|c|c|c|c|c|}
\hline $\begin{array}{l}\text { Kuala } \\
\text { Lumpur } \\
(N=497)\end{array}$ & & $(n=52)$ & $(n=236)$ & $(n=209)$ \\
\hline \multirow{11}{*}{$\begin{array}{l}\text { Kuala } \\
\text { Lumpur } \\
(N=497)\end{array}$} & \multicolumn{4}{|l|}{ Commercial Facilities } \\
\hline & Supermarket & 57.7 & 64.0 & 59.3 \\
\hline & Sundry Shop & 98.1 & 93.6 & 95.2 \\
\hline & \multicolumn{4}{|l|}{ Healthcare facilities } \\
\hline & $\begin{array}{l}\text { Private and Public } \\
\text { Clinics }\end{array}$ & 71.2 & 71.2 & 63.6 \\
\hline & \multicolumn{4}{|l|}{ Recreational facilities } \\
\hline & Playground & 82.7 & 79.7 & 78.9 \\
\hline & Football field & 48.1 & 45.3 & 49.8 \\
\hline & Park/Garden & 7.7 & 13.1 & 17.2 \\
\hline & $\begin{array}{l}\text { Other Support } \\
\text { Services }\end{array}$ & & & \\
\hline & Post office & 46.2 & 43.6 & 42.6 \\
\hline
\end{tabular}


Wan Nurul Mardiah Wan Mohd Rani

Evaluating the Impact of Density on Access to Local Facilities in Urban Neighbourhoods

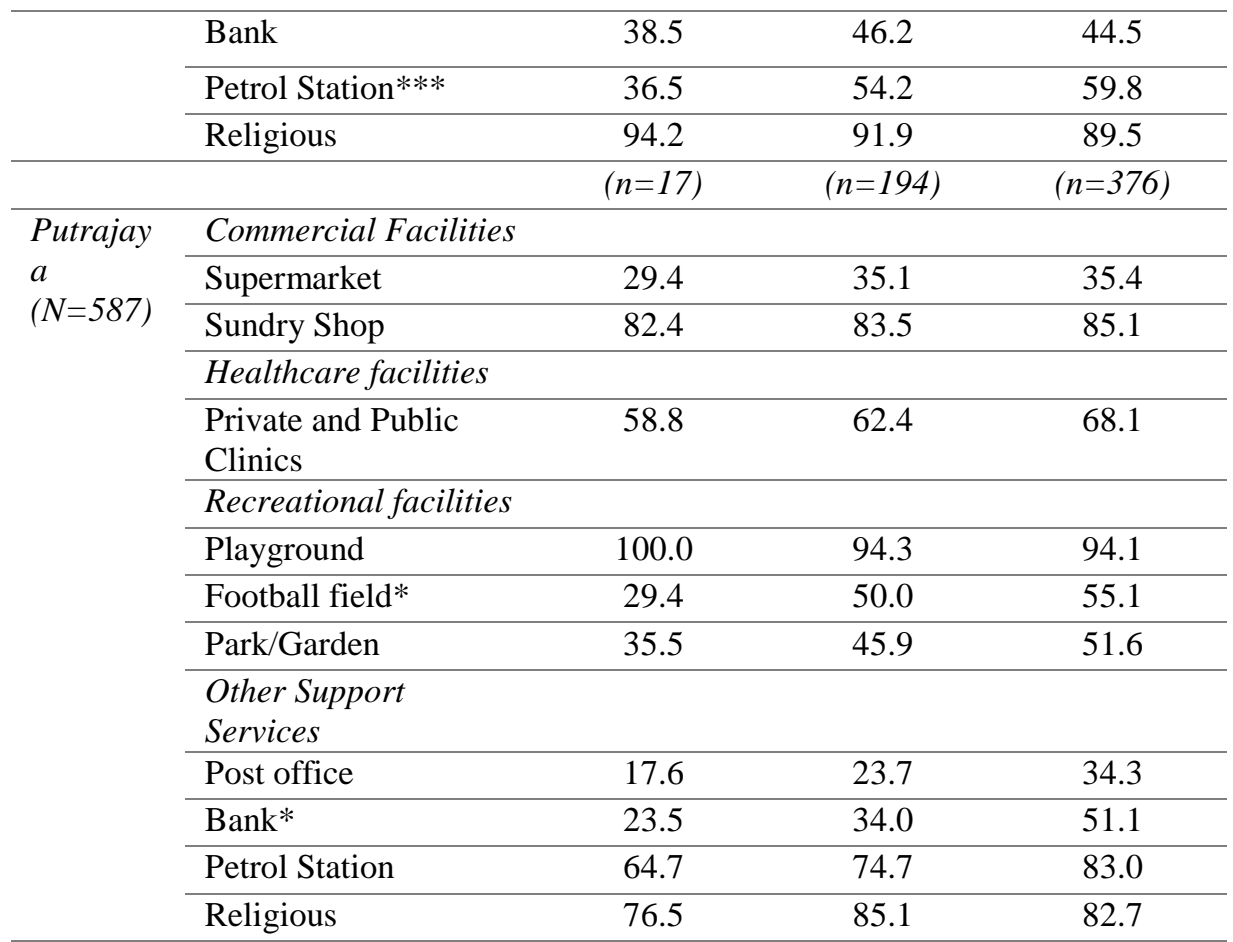

*indicates statistically significant at $10 \%$ level

** Statistically significant at 5\% level

***statistically significant at $1 \%$ level

Generally, car ownership in a particular household is regarded as one of the important factors that would determine the level of accessibility gained by household members (Ferguson and Woods in Jenks and Jones, 2010). On average, most of the respondents in Putrajaya have 2 cars and Kuala Lumpur have 1 car. Table 2 reports the findings on the relationship between car ownership and access to local services and public facilities. However, overall, findings in Kuala Lumpur revealed that there is not much significant pattern on the relationship between car ownership and having good access. This may be due to the various options of public transportation available to serve the residents of Kuala Lumpur besides only a small fraction of household have no car. However, in Putrajaya, for most facilities except for the playground, having at least one car seems to be important to access these facilities. This finding is somehow expected due to the fact that there is limited public transport option and the nature of the zoned layout. On the whole, access towards recreational facilities is better among those that own a car. This finding was reported significant for access to park/ garden at 95\% 
PLANNING MALAYSIA

Journal of the Malaysia Institute of Planners (2014)

confidence level. For other support services, the pattern of findings is quite similar except for religious facilities. For motorcycle ownership, although it is a popular use in most Malaysian cities, owning one does not imply having better access to most of the facilities. It was only reported significant to Putrajaya city specifically to have access to the playground.

\section{Influence of density on access to local services and facilities in Malaysian Cities}

Density has always been associated with access to services because of its influence on the aspect of the viability of a service or facility (Burton 2000; Burton 2003; Rokicka and Warzywoda-Kruszyńska 2006; Bramley, Dempsey et al. 2009; Bramley and Power 2009; Jenks, Jones et al. 2010). Most research hypothesized that density plays a significant role in determining access to the particular service or facilities. The following table 5.3 reveals the three way relationship between case study cities, density and access to local facilities and services. For Kuala Lumpur, finding for commercial facilities were reported significant. Since total $\mathrm{n}$ for low density in Kuala Lumpur is very low $(n=7)$, the researcher only considered results for medium density and high density sub areas. As expected, access to sundry shop facilities was better within the high density areas (96.9\%). Relationship for access to sundry shop in Putrajaya also reports the same finding (89.6\%) and it was also reported to be confidence at $99 \%$ confidence level. Access to recreational facilities was also reported to be significant for Putrajaya's case. Findings revealed that easy access to recreational was greater among those living in low dense areas (98\% and 71\%) particularly the playground and football field followed by medium density $(95 \%$ and $53 \%$ ) and finally the high density (93\% and 48\%). However, after combining data for Kuala Lumpur and Putrajaya, patterns for access to most facilities are more clear and distinct (see Table 5.4). Access to commercial facilities was reported to be easier in high density areas. In lower densities, it was revealed that there are better access to not only recreational facilities but also health care facilities, banks and petrol stations. This may also be influenced by higher car ownership in both cities. Through the use of private cars, residents can easily access services and facilities at a greater distance despite living in low density areas. Previous research such as Breheney (1992), Knight (1996); Stretton (1994); Burton (1997, 2000); Williams (2000); and Bramley et.al. (2009) claimed that higher density areas have better access to services and facilities due to its compactness and proximity. Williams (2000, p. 40) claimed that intensification of urban areas "improve accessibility to services and facilities". It was further added that for retail 
Wan Nurul Mardiah Wan Mohd Rani

Evaluating the Impact of Density on Access to Local Facilities in Urban Neighbourhoods

facilities, higher densities improved access best to shops that serves everyday needs (Williams, 2000, p. 40). Hence, the researcher would likely conclude that density is a significant factor towards having access to certain services and facilities. However, the mixed findings may be further improved when other variables such as demographic variables are being controlled for. In terms of use of the local services and facilities, low density only reports a marginal response, only medium and high density is considered for interpretation. Overall, medium density shows a higher percentage of respondents using the services and facilities in both cities except for sundry shop; religious facilities and banks in Putrajaya and sundry shop in Kuala Lumpur.

Table 4: Relationship between case study cities, density and access to local facilities and services

\begin{tabular}{|c|c|c|c|c|}
\hline & & $\begin{array}{l}\text { Low } \\
\text { density } \\
(n=7)\end{array}$ & $\begin{array}{l}\text { Medium } \\
\text { density } \\
(n=201)\end{array}$ & $\begin{array}{l}\text { High } \\
\text { density } \\
(n=289)\end{array}$ \\
\hline $\begin{array}{l}\text { Kuala } \\
\text { Lumpur }\end{array}$ & Commercial Facilities & & & \\
\hline \multirow[t]{14}{*}{$(\mathrm{N}=497$} & Supermarket $* * *$ & $85.7 \%$ & $47.8 \%$ & $70.2 \%$ \\
\hline & Sundry Shop*** & $85.7 \%$ & $92.0 \%$ & $96.9 \%$ \\
\hline & Healthcare facilities & & & \\
\hline & Private and Public Clinics $* * *$ & $71.4 \%$ & $59.2 \%$ & $74.0 \%$ \\
\hline & Recreational facilities & & & \\
\hline & Playground & $57.1 \%$ & $81.6 \%$ & $78.9 \%$ \\
\hline & Football field & $28.6 \%$ & $44.8 \%$ & $49.8 \%$ \\
\hline & Park/Garden & & $14.4 \%$ & $14.5 \%$ \\
\hline & Other Support Services & & & \\
\hline & Post office & $71.4 \%$ & $42.3 \%$ & $43.6 \%$ \\
\hline & Bank* & $71.4 \%$ & $39.8 \%$ & $47.4 \%$ \\
\hline & Petrol Station & $85.7 \%$ & $55.2 \%$ & $53.6 \%$ \\
\hline & Religious & $85.7 \%$ & $89.6 \%$ & $92.4 \%$ \\
\hline & & $(n=51)$ & $(n=324)$ & $(n=212)$ \\
\hline Putrajaya & Commercial Facilities & & & \\
\hline \multirow[t]{8}{*}{$(\mathrm{N}=587)$} & Supermarket & $33.3 \%$ & $34.3 \%$ & $36.8 \%$ \\
\hline & Sundry Shop*** & $86.3 \%$ & $80.9 \%$ & $89.6 \%$ \\
\hline & Healthcare facilities & & & \\
\hline & Private and Public Clinics** & $76.5 \%$ & $67.9 \%$ & $60.4 \%$ \\
\hline & Recreational facilities & & & \\
\hline & Playground & $98.0 \%$ & $94.8 \%$ & $92.9 \%$ \\
\hline & Football field $* *$ & $70.6 \%$ & $53.1 \%$ & $47.6 \%$ \\
\hline & Park/Garden** & $47.1 \%$ & $53.7 \%$ & $42.9 \%$ \\
\hline
\end{tabular}


PLANNING MALAYSIA

Journal of the Malaysia Institute of Planners (2014)

\begin{tabular}{llll}
\hline Other Support Services & & & \\
\hline Post office & $35.3 \%$ & $29.0 \%$ & $31.1 \%$ \\
\hline Bank & $54.9 \%$ & $42.3 \%$ & $45.8 \%$ \\
\hline Petrol Station & $84.3 \%$ & $80.9 \%$ & $76.9 \%$ \\
\hline Religious*** & $90.2 \%$ & $76.2 \%$ & $92.5 \%$ \\
\hline
\end{tabular}

*indicates statistically significant at $10 \%$ level

** Statistically significant at $5 \%$ level

***Statistically significant at $1 \%$ level

Table 5: Relationship between density and access to local facilities and services

\begin{tabular}{|c|c|c|c|}
\hline & Low density & Medium density & $\begin{array}{l}\text { High } \\
\text { density }\end{array}$ \\
\hline \multicolumn{4}{|l|}{ Commercial Facilities } \\
\hline Supermarket $* * *$ & $39.7 \%$ & $39.4 \%$ & $56.1 \%$ \\
\hline Sundry Shop*** & $86.2 \%$ & $85.1 \%$ & $93.8 \%$ \\
\hline \multicolumn{4}{|l|}{ Healthcare facilities } \\
\hline Private and Public Clinics $* * *$ & $75.9 \%$ & $64.6 \%$ & $68.3 \%$ \\
\hline \multicolumn{4}{|l|}{ Recreational facilities } \\
\hline Playground $* *$ & $93.1 \%$ & $89.7 \%$ & $84.8 \%$ \\
\hline Football field* & $65.5 \%$ & $49.9 \%$ & $48.9 \%$ \\
\hline Park/Garden*** & $41.4 \%$ & $38.7 \%$ & $26.5 \%$ \\
\hline \multicolumn{4}{|l|}{ Other Support Services } \\
\hline $\mathrm{Bank}^{* *}$ & $56.9 \%$ & $41.3 \%$ & $46.7 \%$ \\
\hline Petrol Station** & $84.5 \%$ & $71.0 \%$ & $63.5 \%$ \\
\hline Religious*** & $89.7 \%$ & $81.3 \%$ & $92.4 \%$ \\
\hline
\end{tabular}

\section{CONCLUSIONS}

\section{Implication of the Results}

Overall, the study has revealed the possible impact density may have upon access and use of local services and facilities in residential neighbourhood of two Malaysian cities, Kuala Lumpur and Putrajaya. Among the key findings of the study, in terms of socioeconomic aspects, lower income households generally reported having better access to selected services and facilities within their neighbourhood areas compared to higher income households; this applied particularly to commercial services and recreational facilities in both case study cities. However, the relationship was not as strong as expected. Chi-square results of these relationships were reported only significant for access to supermarket, park, garden and petrol station. In 
Wan Nurul Mardiah Wan Mohd Rani

Evaluating the Impact of Density on Access to Local Facilities in Urban Neighbourhoods

Putrajaya, having one car is generally an important factor to have better access. This corresponds well with the claim made by Ferguson and Wood (in Jenks and Jones, 2010, p.57) that car ownership is an important factor in determining the level of accessibility hence improving access to some if not all local services and facilities. Based on the findings, the study partly supports the hypothesis that "higher density would result in improved access to services and facilities". This is because; the hypothesis does not apply to all types of local services and facilities. Findings revealed that access improved in higher density areas in both case study cities, particularly for commercial facilities. This supports the claims of previous research, including among others, Williams et al. (2000, p. 40) who mentioned that intensification of urban areas has the advantage of improving access to services and facilities and other opportunities. However, for recreational facilities in Putrajaya case is rather different. Households in lower density areas within Putrajaya reported to have better access as compared to households of higher density. Findings from a survey conducted in some UK cities also reported similar findings. Dempsey et al. (2012) reported that higher residential density would have lower public and green space. Provision of public and private green space is better in lower density residential areas. Furthermore, it is important to note that higher density can have negative impacts on community and quality of life (Bramley \& Power, 2009, Bramley et al., 2009).

\section{LIMITATIONS OF THE STUDY}

There are several limitations of this study that the researcher believes have had some impact on the overall outcome. Firstly, the researcher is aware that the nature of the samples for the household survey is one of the limitations in this study. It is noted, that if more time and budget were available, the researcher would have richer data, both in the quantitative sense of having more observations and more variation within the data, and in the qualitative sense that it would be feasible to conduct focus group discussions from local residents of the selected case study areas. Furthermore, the researcher would also gain more information if the scope of the study covered a wider range of locations and types of area. The findings obtained with regard to the access and usage of the services and facilities were only on a perceptual or self-reported basis. Respondents were required to respond to questions in the questionnaire that corresponded to whether they have access to the services and facilities within their neighbourhood. On the usage pattern, it was a self- 
PLANNING MALAYSIA

Journal of the Malaysia Institute of Planners (2014)

reported usage. The respondents were given full responsibility to report their usage pattern. Another issue is the fact that data is only collected at one single time point, which may not be fully represented and will not reveal changes over time. Given these limitations, the findings and implications of the study need to be interpreted with caution. The limitations identified in this study are also aspects that can consider for future research. For example, a future survey might interview households at 1-2 year intervals or ask about the use of services 1-2 years previously, to pick up the aspect of change.

\section{SCOPE FOR FURTHER RESEARCH}

This study has focussed on the influence of density on access to and using local services and facilities. The study was motivated by the fact that it would be of benefit to the municipalities to improve existing cities in order to become more urbanized and at the same time be socially sustainable. Another important implication of this study is it contributes to providing valuable knowledge needed for urban planners and policymakers to meet the challenge of urban growth more effectively and to devise a framework for sustainable urban form to ensure it is socially sustainable. The research findings also contribute to the existing knowledge in such a way that future development and growth in metropolitan regions in developing countries can be guided in a manner that enhances long-term sustainability.

\section{ACKNOWLEDGEMENTS}

This study is part of a PhD research study funded by the Ministry of Higher Education, Universiti Teknologi Malaysia (UTM Q.K130000.2740.00K40) and IHURER, School of Built Environment, Heriot Watt University, United Kingdom. 
Wan Nurul Mardiah Wan Mohd Rani

Evaluating the Impact of Density on Access to Local Facilities in Urban Neighbourhoods

\section{REFERENCES}

Abdul Rahman N., Omar, D., and Salleh, A.G. (2012), Determinant Factors of Neighbourhood Quality, Planning Malaysia Journal of the Malaysian Institute of Planners, Volume X (2012), Page 1-16.

Barton, H and Tsourou, C., (2000), Healthy Urban Planning. London, Spon and Copenhagen.

Barton, H., Guise, R., \& Grant, M. (2010). Shaping neighbourhoods: for local health and global sustainability: Routledge.

Bramley, G. and K. Kirk (2005). "Does planning make a difference to urban form? Recent evidence from Central Scotland." Environment Planning AVolume 37:pp.355-378.

Bramley, G., N. Dempsey, et al. (2009). "Social sustainability and urban form: evidence from five British cities." Environment and Planning A 41(9):pp.2125-2142.

Bramley, G. and S. Power (2009). "Urban form and social sustainability: the role of density and housing type." Environment and Planning B: Planning and Design36(1): pp.30-48.

Bramley, G., Brown, C., Dempsey, N., Power, S., \& Watkins, D. (2008). Social Acceptability. In Sustainable City Form,pp. 105-128.

Bunnell, T., Barter, P. A., \& Morshidi, S. (2002). Kuala Lumpur metropolitan area - A globalizing city-region. Cities, Volume 19, Issue 5, pp.357-370

Burgess, R (2000). The Compact City Debate: A Global Perspective, in Jenks, M. and Burgess, R.(2000). Compact Cities: Sustainable Urban Forms for Developing Countries, Spon Press, Great Britain.

Burton, E., (2003). Housing for an Urban Renaissance: Implications for Social Equity. Housing Studies, 18(4), p.537-562.

Dempsey, N., Bramley G., and Brown C. (2012). The key to sustainable urban form in UK cities? The influence of density on social sustainability. Progress in Planning (77). Elsevier, pp. 89-141.

Dempsey, N., Bramley G., Power S. and Brown C. (2011). The social dimension of sustainable development: Defining urban social sustainability. Sustainable Development, 19(5), pp.289-300.

Dempsey, N. et al., (2010). Elements of Urban Form. In M. Jenks \& C. Jones, eds. Sustainable City Form. Dordrecht: Springer Netherlands, pp. 2151.

Federal Department of Town and Country Planning, Peninsular Malaysia (2006), National Urbanisation Policy, Ministry of Housing and Local Government, August 2006.

Government of Malaysia (2005), National Physical Plan (NPP).

Jabareen, Y.R., 2006. Sustainable Urban Forms. Journal of Planning Education and Research, pp.38 -52. 
PLANNING MALAYSIA

Journal of the Malaysia Institute of Planners (2014)

Jenks, M., Jones, C., Dempsey, N., Brown, C., Raman, S., Porta, S., et al. (2010). Elements of Urban Form. in Dimensions of the Sustainable City (Vol. 2, pp. 21-51): Springer Netherlands.

Jenks, M., Burton, E. and Williams, K. (eds) (1996) The Compact City: A Sustainable Urban Form? E \& FN Spon, an imprint of Chapman and Hall, London.

Jones, C., (2009). Dimensions of the Sustainable City, Springer.

Asian Studies Association of Australia in association with NUS Press and NIAS Press.

Kuala Lumpur City Hall. (2004) Kuala Lumpur Structure Plan 2020.

Kuala Lumpur City Hall. (2008) Local Plan, Kuala Lumpur 2020 City Plan.

Lin, J. J., \& Yang, A. T. (2006). Does the compact-city paradigm foster sustainability? An empirical study in Taiwan. Environment and Planning B: Planning and Design, 33(3), 365-380.

Lotfi, S., \& Koohsari, M. J. (2009). Measuring objective accessibility to neighborhood facilities in the city (A case study: Zone 6 in Tehran, Iran). Cities, 26(3), pp. 133-140.

Malaysia, 2010. Tenth Malaysia Plan 2011-2015.

Malaysia, 2005. Ninth Malaysia Plan 2006-2010.

Newman, P. and J. Kenworthy. 1999. Sustainability and cities: Overcoming automobile dependence. Washington, DC: Island Press.

Porta S (2001).Quantifying the contribution of form to urban (social) sustainability, Paper presented in Conference Australia: Walking the $21^{\text {st }}$ Century, $20^{\text {th }}$ to $22^{\text {nd }}$ February 2001, Perth Australia.

Richardson H.W., Christine Bae, C.H and Baxamusa, M. (2000) Compact Cities in Developing Countries: Assessment and Implications in Burgess $\mathrm{R}$. and Jenks, M. (2000), Compact Cities: Sustainable Urban Form for Developing Countries, Spon Press, Great Britain.

Rokicka, E. and W. Warzywoda-Kruszyńska (2006). Social Justice and Social Inequalities - Analysis of the Public Discourse in Poland. Soziale Gerechtigkeit: 285-301.

Talen, E. (2008). New Urbanism, Social Equity, and the Challenge of PostKatrina Rebuilding in Mississippi. Journal of Planning Education and Research, pp.277-293.

Talen, E. (1999). Sense of Community and Neighbourhood Form: An Assessment of the Social Doctrine of New Urbanism. Urban Studies, Vol. 36, pp. 1361-1379 
Wan Nurul Mardiah Wan Mohd Rani

Evaluating the Impact of Density on Access to Local Facilities in Urban Neighbourhoods

Towers, G. (2005). An introduction to urban housing design: at home in the city: Architectural Press.

Williams K. (2000). Does intensifying cities make them more sustainable? in Williams, K, Burton E\& Jenks, M. (Eds) Achieving sustainable urban form, (London: E \& FN Spon).

Williams K., Burton E., and Jenks M. (Eds) (2000).Achieving sustainable urban form, (London: E \& FN Spon). 